\title{
Potential Space
}

\section{Katrina DeBonis ${ }^{1}$}

Received: 21 November 2019 / Accepted: 12 February 2020 / Published online: 2 July 2020

(C) Academic Psychiatry 2020

I was a first year medical student when I was introduced to the concept of a potential space. In turning that phrase over in my mind, I was captivated by the idea of two membranes between which no space typically exists, but under certain circumstances can fill with fluid, bacteria, air, or crystals. In my 9 years as an attending psychiatrist, I have returned to the metaphor of potential space to describe the ways in which my work has changed me - creating and filling spaces that hold something that did not exist before.

Over the last few years, I have had the opportunity to learn from medical students and trainees who have helped create a space in which the principles of justice, equity, diversity, and inclusion have transformed from being logically understood and supported to more deeply held values carrying the necessary emotional charge to change a system defended against it.

In a classroom where I organized the foundational curriculum on brain and behavior and invited lecturers to illustrate the differences between mature and immature defense mechanisms, I was oblivious to the microaggressions students were suffering. After class, a student pointed out to me that when the hands of white students were raised, their questions were answered immediately. When Black students raised their hands, they were sometimes ignored, sometimes asked to wait until the end of class. My reflex was to defend the instructors because I wanted to believe they were making innocent mistakes. I identified more with the teachers than with the students and thought, "it's true...this generation really is too sensitive. Do I even want to keep teaching?" These thoughts were accompanied by an aching sense of misalignment that grew over the subsequent days and weeks.

Luckily, through my psychiatric training, I learned enough about unconscious conflict to suspect that this defensive initial reaction was serving to protect my fragile ego from the pain of recognizing that I might not be as good of a person as I like to

Katrina DeBonis

kdebonis@mednet.ucla.edu

1 University of California, Los Angeles, CA, USA think I am. Doctors, with our identities strongly linked to helping others, may have a particularly difficult time recognizing when we are harming. Our knowledge as psychiatrists helps provide us with a way to resolve unconscious conflicts: we need to bring what is hidden to light, what is unconscious closer to awareness. My students and trainees expended their emotional energy, at an expense to their own wellbeing, to help me see what I could not at first. Listening to them while intentionally bringing awareness to my own feelings and defenses - most of which were very unpleasant to see-has led me to notice the injustice around me that I had previously not seen, or if I had seen, had not felt. As those membranes of ignorance separated and allowed for me to see the ignored hands, I felt pain imagining the experience of minority students and trainees, guilt that I had been complicit, shame that I, someone who took pride in my sensitivity to others, had been so clueless.

Regardless of intentions, our brains empathize more with some than with others. This affects our ability to connect, and in our line of work, to heal. I was not able to appreciate the deficits in my empathy, this walled off potential space, until it started to enlarge and fill. Now, I can feel its presence enhancing many aspects of my life including my clinical work. I recently had a Black woman tell me, "I didn't think I could work with a white psychiatrist, but you're ok." I take this to mean that I am making progress, while regretting that there have likely been many patients over the years who did not feel that I could see them fully and did not feel safe telling me so. I know that there is a lot of work for me to do, a lot I still cannot see, but I can feel that my empathy is deeper and broader, and that I am a better psychiatrist and human because of it.

I trust that any psychiatrist strives to be unbiased in their clinical work, as well as in their teaching and mentoring of students and trainees. But we have blind spots we cannot see and potential spaces we have not explored. We have a biased unconscious defending us by denying our role in the marginalization of other humans. Our field, with its painful history of discrimination, alongside its foothold in the scientific and theoretical exploration of the unconscious and behavior, has the unique potential to lead in understanding and addressing 
racism. When it comes to ideals as important as justice, equity, diversity, and inclusion, we must allow ourselves to be challenged by the next generation of physicians, reflect meaningfully on our resistance and defenses, and do the necessary work of educating ourselves through reading, listening, and honest conversations.

As we teach, we learn. Nowhere has this been more powerful than while working alongside residents involved in justice, equity, diversity, and inclusion at my institution. They have bravely led efforts to improve the curriculum, reduce workforce disparities, and enhance patient care. As a novice, I have led from behind with help from many generous, patient teachers around me. We urge our students and residents to have a growth mindset - to stretch and challenge themselves, and reflect and learn from mistakes. As teachers, clinicians, and mentors, we must demand the same of ourselves. Our students have much to teach us if we simply allow for the opening. Actualizing our potential empathic spaces will not always be pleasant, but once there, our only regret will be having been without it for so long.

Acknowledgments The author would like to express gratitude for many generous and patient teachers including Drs. Nicolás Barceló, Sonya Shadravan, Michael Mensah, Gail Wyatt, Xavier Cagigas, Eraka Bath, and the JEDI residents and faculty at UCLA.

\section{Compliance with Ethical Standards}

Disclosures The author states that there is no conflict of interest.

Publisher's Note Springer Nature remains neutral with regard to jurisdictional claims in published maps and institutional affiliations. 